\title{
The prevention of spinal injuries in rugby football
}

\author{
J R Silver MB BS FRCP(Ed and Lond $),{ }^{1}$ D Stewart LLB ${ }^{2}$ \\ ${ }^{1}$ Emeritus Consultant in Spinal Injuries, Stoke Mandeville Hospital, Mandeville Road, \\ Aylesbury, Buckinghamshire HP21 8AL, England; ' 2 tewarts Solicitors, 63 Lincoln's Inn \\ Fields, London WC2A $3 L W$, England.
}

The incidence of injuries to the spinal cord sustained at rugby in South Africa, New Zealand and Australia is reviewed. Ninety-seven injuries seen at Stoke Mandeville Hospital at the National Spinal Injuries Centre (NSIC) between 1956 and 1993 are analysed in detail. There were 93 accidents at rugby union, two at American football and two at rugby league. The injuries were of the cervical spine apart from four hysterics and one thoracic injury. The thoracic injury occurred after the game when the player fell downstairs. The injuries were analysed according to the mechanism of injury, the neurological condition, the causation, the standard of the player and the position in the field. The injuries caused were the result of force being applied to the skull which was transmitted to the cervical spine resulting in injury to the cervical cord. As a result of this research, representations were made to the appropriate authorities and changes in the laws were made. As a result of these law changes there has been a dramatic reduction in the overall number of injuries and the elimination of the injury from the loose scrum. This paper discusses the historical sequence of how these preventative measures came about to reduce the incidence of injuries and the legal implications whereby the authors took part in two law suits. The legal consequences are analysed in detail.

Keywords: rugby football; spinal injury; prevention of spinal injury.

\section{Introduction}

Rugby is a popular game and is played in over 100 countries. Because of its nature, injuries inevitably occur. It is very difficult to determine what the true incidence is, and also difficult to compare figures because the methods of collection are not the same.

Between 1954 and 1993 there have been 226 papers published on injuries sustained in rugby football. Some are isolated case reports and others deal with schoolboy injuries. . $^{1,3}$

The conclusion was that rugby was the sporting activity most likely to give rise to injury. It is not sprains, bruises and bumps that are a worry, it is the incidence of death and serious injuries to the cervical spine. This has given rise to concern all over the world, and particularly to spinal injuries consultants who have to look after the patients with their initial injury, and to be responsible for the long term care of these patients for the rest of their lives. A particularly distressing aspect is explaining to the relatives of these young people the implications and consequences of these injuries.

\section{Incidence}

\section{South Africa}

Scher $(1990)^{4}$ reported on the spinal injuries (all tetraplegics) admitted to the Conradie Spinal Unit in South Africa. During the period 1964-1980, 50 rugby players with cervical spinal cord injury were admitted, an average of three players a year. During the period 1981-1987, 38 players were admitted-an average of 5.4 players per year. He concluded that despite increased public awareness of serious rugby spinal injuries and considerable amendments to the rules, the incidence of rugby spinal cord 
injuries in the Cape province has not decreased.

\section{New Zealand}

In New Zealand, rugby injuries have been recorded since 1973. In 1979 Calcinai $^{5}$ initially found an average of nine serious spinal injuries per year. This resulted in a change in the tackle law and from 1980 to 1984 the number of serious neck injuries had dropped to six per year.

In New Zealand where the game is a religion, these figures caused considerable distress among the mothers. It culminated in one Black Weekend in May in 1979 when four players were injured. One died, two had complete tetraplegia and one partially recovered. The incidence was so high that in the Otaro Unit the commonest cause of admission for the 3 years preceding 1980 was a rugby injury of the spinal cord. This exceeded the admissions from road traffic accidents. In 1 year there were five fatalities from rugby. This concern resulted in local law changes in New Zealand to stop charging in the scrums and recommendations for the players to strengthen their neck muscles.

\section{Australia}

In 1987 Geoffrey Vanderfield ${ }^{6}$ reported on the experience from New South Wales in a retrospective study of 45 rugby football injuries admitted to the spinal unit at the Royal North Shore Hospital between 1968 and 1985 under the care of Dr Yeo.

\section{United Kingdom}

One of the authors has been looking after patients with spinal injuries since 1956 at the National Spinal Injuries Centre (NSIC) and the Merseyside Regional Centre. In the early years there was only one serious spinal injury from rugby every 4 years. When confronted with an occasional injury of such rarity, the conventional wisdom was accepted as being 'the luck of the game' or 'an act of God' and the rarity made it difficult to see any pattern or carry out any research. However, there seemed to be a dramatic increase in the injuries from 1970 onwards, reaching the peak of nine injuries in the
1980/1981 season. As some of the patients were still present when the following season began, at one stage there were 13 players with broken necks in the NSIC. This constituted the commonest cause of admission from organised sport in the NSIC. ${ }^{7}$

\section{Experimental work}

A series of papers were written. ${ }^{2.7}$ The methodology of the earlier papers was followed (a personal interview and a structured questionnaire) and the information has been brought up to date for the purpose of the present paper. The following data represent the cumulative experience from 1952 until the beginning of the 1993/1994 season (Table I).

\section{Injuries and how they were sustained}

There were 97 players. The majority were treated personally as acute injuries, either at the Liverpool Paraplegic Centre (1965-1970) or the National Spinal Injuries Centre, Stoke Mandeville Hospital (1970-1993). All cases seen at Stoke Mandeville from 1952 were included. Because of the interest of the medical author, some came as secondary referrals. Ninety-three were playing rugby union football of which four were hysterics/malingerers. Two were playing rugby league and two American football.

\section{Neurological condition}

Among the 93 players injured while playing rugby union football the majority had cervical cord injuries of which equal numbers were complete and incomplete. Four had root injuries which were also severe. There were four hysterics/malingerers. The only thoracic injury was sustained off the playing field. The patient fell down a flight of stairs whilst drunk, after the game.

\section{Anatomical factors and mechanism of injury}

When the study was made in 1984 it revealed that injuries to the thoracic and lumbar vertebrae from knocks, kicks, or blows during a game do not give rise to damage to the spinal cord or roots, but the 
Table I Number and type of player injured and level of injury 1956-1982, 1982-1987 and 1987-1993

\begin{tabular}{|c|c|c|c|c|}
\hline & 1956-1982 & $1982-1987$ & 1987-1993 & Total \\
\hline \multicolumn{5}{|l|}{ Game } \\
\hline Rugby Union & 63 & 19 & 11 & 93 \\
\hline Rugby League & 2 & & & 2 \\
\hline US football & 2 & & & 2 \\
\hline \multicolumn{5}{|l|}{ Level of injury } \\
\hline Cervical & 48 & 18 & 9 & 75 \\
\hline Root & 4 & & & 4 \\
\hline Thoracic & 1 & & & 1 \\
\hline No cord injury & 7 & & & 7 \\
\hline Unknown & 2 & & & 2 \\
\hline \multirow[t]{2}{*}{ Hysteric } & 1 & 1 & 2 & 4 \\
\hline & & & & 93 \\
\hline Schoolboys & 20 & 3 & 2 & 25 \\
\hline Deaths & 4 & 1 & 0 & 5 \\
\hline
\end{tabular}

cervical cord is particularly vulnerable to injury.

The cord in the lumbar and thoracic region is protected by sturdy vertebrae and thick muscles. The cervical vertebrae are less sturdy than the thoracic ones.

In rugby, players lead with their heads (Fig 1) and when the head strikes the ground the force is absorbed by the skull and the higher vertebrae and diminshes progressively lower down the vertebral column. The likelihood of damage occurring to the cervical vertebrae is enhanced by the disparity in the movements of the unsupported skull on the cervical spine. The

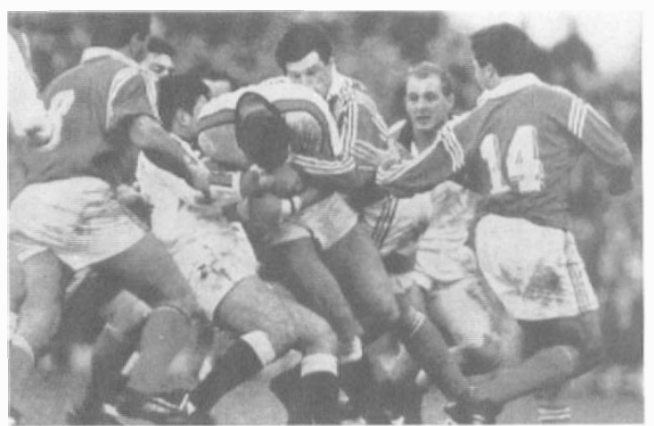

Figure 1 Rugby players lead with their heads. When a powerful player such as Bayfield is partially restrained and then released there is ample force to fracture or dislocate the spine. (With acknowledgements to The Mail on Sunday.) danger of dislocation occurring is further increased by the alignment of the facets, which in the upper cervical spine do not present such resistance to dislocation as the vertebrae lower down because their facets are aligned less obliquely.

Flexion. When a force is exerted through the crown of the head it is transmitted through the skull to the cervical vertebrae, resulting in crushing of the vertebrae and extrusion of the vertebral body and disc material posteriorly into the cervical cord. Dislocation may occur without any fracture of the vertebrae. Roaf, ${ }^{8}$ using cadaveric spines, was unable to produce dislocation without a fracture by hyperflexion alone and found that some rotation must be present. Bauze \& Ardran, ${ }^{9}$ in a critical and fundamental paper, solved this problem by showing that when the vertex is fixed (being locked on the ground, a common occurrence in rugby) far less force is required to dislocate the vertebrae and dislocation can occur without fracture (a mechanism of injury reproduced and repeated on the rugby field). Recent studies of dislocations using an MRI scan have shown that a bifacetal dislocation is frequently associated with damage to the disc and prolapse of damaged disc material which can injure the cord. ${ }^{10}$ 
Spearing. This is a method of tackling in American football (now illegal) when the head was used as a weapon to drive into the opponent. This may occur in rugby union by accident when the crash tackle is performed. Instead of the head being positioned correctly behind the thigh it is misplaced either because the tackled dodges or the tackler mistimes his tackle so that the head strikes the abdomen, the thigh or chest. The force of the blow to the head can be absorbed by the brain and result in instantaneous respiratory and cardiac arrest, or it may be transmitted to the spine giving rise to tetraplegia.

Extension. The anterior posterior diameter of the spinal cord is reduced during extension of the cervical spine so that when the neck is forcibly extended the spinal cord is compressed between the discs and vertebral bodies anteriorly and the lamina and ligaments posteriorly (tetraplegia without bony injury). ${ }^{11}$ The cord can thus be injured without there being any overt fracture or dislocation - the so called 'extension' injury. Torg $^{12}$ has developed this concept whereby transient tetraplegia can occur in footballers with a narrow cervical vertebral canal.

These observations made in 1984 on the mechanics of injury remain true in 1994 but they have been amplified by two further developments that have enhanced our knowledge.

\section{Rapid transfer by helicopter}

This has enabled us to see patients straight from the rugby field within hours of injury and the transient spinal cord concussion as described by Torg ${ }^{12}$ in the USA has been recognised in rugby players.

\section{The ability to scan the cord}

Initially, under the dominant influence of Sir Ludwig Guttmann, a nonsurgical approach was adopted in the management of traumatic spinal injuries in the United Kingdom. Consequently our knowledge of spinal cord pathology was limited as there were no operative findings, few postmortems, and myelography was thought to be contraindicated in acute spinal injuries. The development of the MRI and CT has enabled us to scan the cord noninvasively and this is now routine at the NSIC. The role of disc damage first delineated by $\mathrm{Sir}$ Charles Symonds ${ }^{13}$ is being acknowledged/ rediscovered. Apart from a massive disc prolapse seen in unifacetal and bifacetal dislocation, less severe degrees of damage are being recognised.

The whole concept of the stability of the vertebral column has now been placed on a rational basis according to the three column concept of Dennis ${ }^{14}$ and the management of traumatic cervical injuries, of which rugby is a small but important cause, can now be based on scientific principles. The significance of minor disc damage and minor instability can now be evaluated.

\section{Number and type of player injured correlated with the mechanism of injury 1956-1982 (before the laws changed) and 1982-1993 (after the laws changed)}

\section{Standards \\ 1956-1982}

Of the 67 games in which injuries were sustained, three were of first-class standard, 34 were club games, 12 were school team games, four were other school games, and three were practice games; in 11 cases the standard of the game was not known or not relevant. Seven schoolboys were injured in games with adults.

1982-1993

Only two patients were members of a first-class club and both were playing for their third teams. The rest were second- and third-team players from second-class clubs. Two were injured in training sessions and two of the five schooolboys were injured in games played against adults. Two of the schoolboys were injured in school matches.

\section{Conclusion}

A striking difference between the two periods is evident. In 1956-1982 many players were from first-class club and school 1st XVs. The injuries occurred during competitive games, whereas in the later period the players were of a considerably lower standard, implying less skill and fitness. 
Players injured in scrums

1956-1982

Between 1956 and 198215 players were injured in scrums, 14 while playing rugby union and one while playing rugby league. Only one player was a second row forward, which indicates the dangers of playing in the front row. Three players were injured at the formation of the scrum as a result of extension or forced flexion of the neck, eight were injured when the front row collapsed and the second row continued to push and this fulfils the mechanisms required by Bauze \& Ardran: ${ }^{9}$ when the head is locked on the ground less force is required to dislocate the neck than if the neck was free. Of the remaining players, two (one of whom was a malingerer) were injured when the scrum collapsed and in the remaining case the mechanism of injury was not known. Collapse of the scrum may be due to a discrepancy of strength and skill or may be deliberate.

\section{2-1993}

Between 1982 and 199311 players sustained injuries in scrums. The majority were front row forwards. One was injured when the players charged at each other in contravention of the laws. Two players were inexpert and had not played in their positions before, or were overmatched. The other cases all followed a collapse of the scrum after which the second rows continued to push. One hooker's shoulder struck the ground. His spine was hyperextended - there was a tearing noise and he experienced a transient paraplegia. No convincing fracture was ever demonstrated. He subsequently also turned out to be a malingerer.

\section{Conclusion}

It would appear that the method of injury is unchanged and players are still sustaining dislocations of the cervical spine and are still at risk when playing in the front row of the scrum.

\section{Players injured in tackle 1956-1982}

Between 1956 and 198214 players were injured when they were tackled while carry- ing the ball; four of these tackles were illegal. An example of an illegal tackle was when a player was strangled by an opponent who broke his neck in a 'friendly' match. Four players were injured as a result of a multiple tackle. It was not clear in some cases whether the neck was broken in the tackle or in the ensuing pile up. Four players were injured when their heads struck the ground violently. One player speared himself.

\section{2-1993}

Between 1982 and 1993 seven players were injured while tackling. One schoolboy suffered an illegal high tackle and two other players struck their heads while tackling their opponents.

\section{Conclusion}

The mechanism of injury appears unchanged.

\section{Players injured in ruck and maul 1956-1982}

Between 1956 and 198220 players were injured in a ruck and maul. Of these, 15 were forced to the ground and either their own side continued to push on their buttocks so that their heads were driven into the ground or players piled on top of them in an attempt to kill the ball. One player described how he felt a click as his head struck the ground, followed by severe pain and paralysis as supporting forwards pushed on his buttocks, raising his hips. Two players injured themselves by trying to force their way through other players and striking their heads. One player was kicked and another deliberately strangled. More forwards than other players are injured in rucks and mauls because they actively seek out the ball there. The number of injuries incurred in rucks increased strikingly between 1973 and 1982, none having occurred before 1970 .

\section{2-1993}

Between 1982 and 1993 seven players were injured in a ruck and maul, the last one in 1986. In each case, while stooping to pick up a ball, they were pushed to the ground; 
other players piled on top and they were driven into the ground while their necks were forcibly flexed.

\section{Conclusion}

The change in the ruck and maul laws whereby players were not allowed to collapse the loose scrum to the ground has eliminated this injury.

\section{Fitness}

1956-1982

General. Nine players were injured probably because they were not fit enough. Four players claimed that they were not generally fit to be playing any kind of sport; one was a patient with schizophrenia, who went straight from hospital to his local rugby club, asked for a game, and was immediately injured. One player turned up at his club before the season had started, not intending to play, and played in a practice game in an unfamiliar position (the front row) on a wet pitch in training shoes against the first team. Five players were injured in the first game of the season.

Specific. Three players were injured because they had not received sufficient specific training: a wing three-quarter was made to play as a front row forward because of his strength and general ability but was unable to cope with the particular skills required; a schoolboy who had played only three or four games of rugby was put in the first team and was injured in a maul and ruck in a match between schools; and another player had played for only half a season.

\section{$1982-1993$}

General. One player, aged 43 years and who was not fit, was injured during a tackle. Another player aged 33 years, who had retired from rugby some two seasons before was at a match to run the line but came on for half a game when a player on his own side went off injured. One other player had been out of the game and had come to referee but was persuaded to play.

Of the 30 players, only two were members of first-class clubs and others were playing for junior sides. This implies a lesser degree of fitness and skill at this level.

\section{Conclusion}

Despite the introduction of leagues, competitive rugby and the emphasis on being fit to play, rugby players are still turning up to play in an unfit state. The importance of being trained for a particular position, especially the front row, is not appreciated in the lower echelons of rugby (Fig 2).

\section{Summary of the research}

In 1984 as a result of the earlier research, laws were introduced to prevent the head striking the ground. This was achieved by making it illegal for the head to dip below the waist. The emphasis was that players should stay on their feet. The loose scrums were not to go on too long and players were not to pile on. Mismatch of skills and strength, particularly by schoolboys in the set scrum were to be avoided.

The results were as follows.

1 The number of acute admisssions to the NSIC with tetraplegia as a result of injuries sustained while playing rugby has fallen.

2 The epidemic of ruck and maul injuries which commenced in 1975, reaching epidemic proportions in 1980, has almost ceased with the law changes, resulting in a more fluid game which is more enjoyable to watch (Fig 3 ).

3 The number of injuries in scrum and tackle has remained relatively constant.

4 The tackling injuries are mostly due to

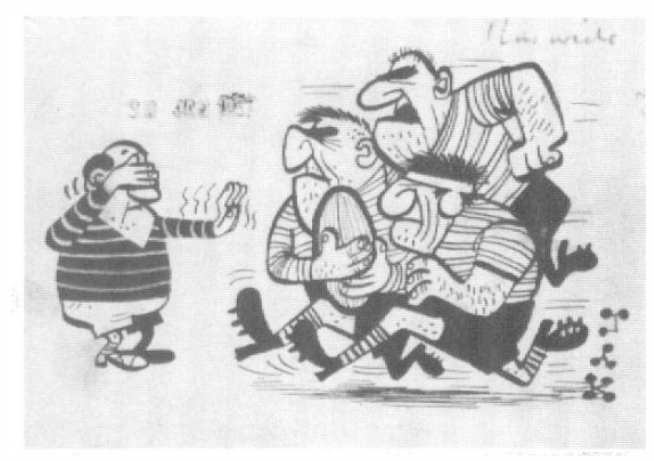

Figure 2 Unfit players are likely to get injured. 


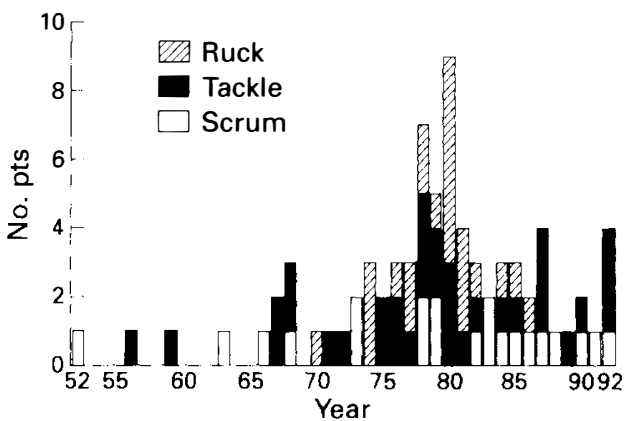

Figure 3 Numbers of injuries occurring in set scrums, tackles, rucks and mauls in rugby union football 1952-1992/93. Acute admissions to the NSIC reported year by year by the medical author. The injuries were very rare until 1975. There was an epidemic of ruck and maul injuries which disappeared owing to the change in the laws. The scrum and tackle injuries have remained relatively constant.

bad luck when someone dodges or when the head strikes the thigh.

5 The scrum injuries are the result of the scrum collapsing for various reasons.

6 The distribution of the injuries has changed with regard to fitness. In the earlier studies many of the injuries were in first-class players, whereas in the latter studies the players were in the lower echelons of the game, implying less fitness and less training.

7 Injuries due to stupidity have ceased.

8 Injuries due to the mismatch of strength and skill have ceased. The importance of players being of equal standard in the front row of the scrum, particularly at schoolboy level, has been appreciated.

9 The detection by means of a MRI of narrowing of the cervical vertebral canal and the detection of undue mobility of vertebrae has shown latterly the importance of minor degrees of injury to the discs.

10 Now a rugby player who has sustained an injury to his skull resulting in a painful neck without neurological involvement can have a scan performed and it has been frequently shown that there is damage to the disc which puts the player at risk if he carries on playing rugby.

Despite the fact that these are young fit players, without the major associated trauma seen in road traffic accidents, who are rapidly transferred to specialised units, there is a high death rate (5 in 97 and there has already been a death in the present season), compared with a nonselected series of 166 consecutive tetraplegic admissions over an 11-year period ending in 1981 reported by Ravichandran \& Silver. ${ }^{15}$ At the NSIC there were only four deaths.

11 The extremely rare phenomenon of an ascent of the lesion to involve the brainstem due to swelling of the cord has been seen in these rugby players on two occasions.

12 The high incidence of hysteria/malingering ( 4 out of 97), compared with 20 cases out of 7000 total admisssions of whom 5000 were traumatic admisssions at the same centre until 1987. ${ }^{16}$

\section{Legal aspects}

A spinal injury causing tetraplegia where compensation is payable, such as in road traffic accidents, can attract damages of over $£ 1$ million. It is hardly surprising that with such large sums of money involved there have been attempts made to obtain compensation by means of law suits.

The English experience of litigation regarding rugby injuries is significant although not extensive. When someone is seriously injured playing a sport like rugby there are a number of possibilities.

1 The accident victim may be entitled to take proceedings for compensation for the tort of assault against the other player. Such an entitlement arises if the injury was sustained as a result of a deliberate foul as opposed to the rough and tumble' inherent in a contact sport. Someone voluntarily playing the game of rugby is regarded as having consented to the risk of such bumps and bruises (and even more serious injuries) which can arise through the fault of no one.

2 Additionally, if the injury arose from a deliberate foul, there may be a criminal element involved whereby the accident victim finds himself as a witness for the 
prosecution in proceedings taken by the police or against the assailant. Such prosecutions are rare but not rare enough or, looked at another way, do not occur often enough. There are too many deliberate fouls in the game. The penalty from the court against a convicted player will depend on the circumstances ranging from a fine through to imprisonment.

3 If a player is injured as a result of a deliberate and unprovoked assault causing serious substantial injury then there is likely to be an entitlement on the part of that player to make a claim against the Criminal Injuries Compensation Board which pays compensation to victims of criminal offences. There is no double compensation. If the player can get redress by way of compensation as a result of his own law suit, then one sum is used to counterbalance the other.

4 The injured player may have an entitlement to take proceedings against a number of different persons or bodies depending upon the circumstances. These can include (a) his school; (b) the opposing team's school; (c) the referee; (d) the team coach; (e) his rugby club; (f) the opposing team's rugby club; (g) the emergency services (or others) if the first aid is carried out in an improper manner thereby aggravating an injury; (h) the owners or controllers of the playing area (if the injury was caused needlessly by an unsafe pitch).

\section{Civil liability of schools and school authorities}

A player at school is entitled to take proceedings against his school or the opposing school if the injury arose through negligence. This means proving a duty of care, a breach of duty and damage resulting. It is not as easy as it sounds. The courts are reluctant to place too heavy a burden on those in authority whilst running a game which is inherently likely to cause injuries to some degree whether safely run or not. Nevertheless, if a schoolboy can demonstrate, on the balance of probabilities, the type of factors listed below, then the seeds of a successful claim for compensation can develop.

Inadequate coaching

Unevenly matched teams with regard to size, weight and experience

Lack of proper warm up

Lack of proper pre-match fitness

Unsuitable playing conditions

Unsuitable first-aid arrangements

Lack of teaching of the laws of the game (which may lead to one player unwittingly injuring another through ignorance-as has happened)

Inadequate refereeing

Over-psyching up. The need and the desirability of achieving a peaking and a high level of desire to win is appreciated in all forms of sport. This is perfectly acceptable provided the game is played within the laws. There is no possible place for such motivation which is designed for, or can result in harm or injury to the opposition.

This list is not intended to be exhaustive. It must however be assumed that many judges will approach the litigation cautiously and instinctively on the basis that most injuries in sport are caused through sheer bad luck. Nevertheless, far too many of the most serious injuries in rugby are ones which could have been avoided if schools or clubs involved had adopted higher standards of care.

Various court cases have been run by the legal author of this paper. The highest profile case was that of Van Oppen v. The Trustees of Bedford School (1989) 1ALL ER 273. The pupil was seriously injured in 1980 when 16 years old. The claim was pursued on two alternatives: firstly with regard to the duties of the school to make sure that the injury itself was avoided and secondly with regard to the failure of the school to advise the boy's parents of the need to take out insurance protection against sheer accidents. The question of insurance is not dealt with in this paper.

The case was lost, but nevertheless the decision and the legal principles involved gave encouragement for another lawsuit (Quinn v. Devon County Council) to be pursued by a different judge. This was on behalf of a pupil at college who sued the 
local authority responsible for management of the game when he fractured his spine in two places. Again similar allegations regarding lack of coaching, over-psyching and lack of a warm-up were paraded before the judge who, after about 5 days of strong evidence about the way in which the team had been coached, gave very strong hints that he wanted the claim settled. Negotiations then took place and a case which could have been a landmark decision against a local authority was buried on terms which remain confidential.

Based on those two cases, and particularly the case of Quinn, there have been a number of other claims pursued which have not proceeded to trial but where negotiated settlements have been achieved in favour of the injured person.

\section{Historical sequence resulting in the law changes}

1 In January 1979 one of the authors had looked after 30 players with broken necks from rugby at the NSIC and he currently had five patients under his care. He wrote a letter to the British Medical Journal and identified the following factors causing injuries: ${ }^{17}$ (a) boys were injured playing against adults, (b) there was a mismatch of skill in the front rows of the scrums, (c) illegal play and (d) psyching-up

2 This was picked up by Kincade, ${ }^{18}$ a headmaster in Northern Ireland who wrote to all the headmasters in Northern Ireland endorsing these recommendations.

3 This was followed up by the medical officers of schools (MOSA) who sent round a circular endorsing these views, in addition recommending strengthening of the neck muscles and first-aid measures. ${ }^{19}$

4 The findings were again presented to MOSA in a key meeting in May 1979 and with these recommendations in front of them they reaffirmed the advice that teams should be selected with regard to height and weight, and that they should take out accident insurance. The advice given by MOSA in 1974 that junior rugby teams should be selected by weight rather than age should be re-emphasized, along with the fact that a third of the injuries had occurred as a result of collapsing in the scrums. ${ }^{19}$ This was signed by the president, the secretary, and the three doctors, J R Silver, J E Davies and L Walkden, who had all made presentations to the meeting. These recommendations were welcomed at the meeting by the doctors, who all affirmed that the game they dreaded most was the game between schoolboys and the old boys. Immediately many of the schools ceased to allow the annual match between the schoolboys and the old boys which was an occasion for settling old scores and also for drinking. This created a furore at the Rugby Union Headquarters because the schools are the life-blood of rugby union in England and they were stimulated to take notice.

5 In March 1981 there were 13 rugby players with broken necks who were patients at the NSIC. The patients were so concerned about their plight that they wrote to all the former patients at Stoke Mandeville who had broken their necks playing rugby and a meeting was held at the NSIC, Stoke Mandeville. This was attended by Dr Walkden (medical officer, RFU), Mr Uttley (former international), who was coach to the national side, $\mathrm{Mr}$ Blakeway (former international), and Dr Lewis Cannell, former captain of England. Attention was again drawn to the inadequacy of insurance and the need to make the game safer (Figs 4, 5).

6 A joint meeting was held between doctors, rugby players and administrators in 1983 at the Chiltern Hospital (Fig 6). Amongst other presentations on safety the data ${ }^{2}$ were again presented. This meeting was attended by Mr Beer, chairman of the Rugby injuries subcommittee (now president of the RFU), Mr Kendal Carpenter, president of the RFU, Mr Rutherford (technical advisor), Douglas Stewart (solicitor), numerous neurosurgeons and neurologists, referees and players. The sense of the meeting was that the game must be made safer. Having enlisted the support of such an influential body, the English Rugby Union took 

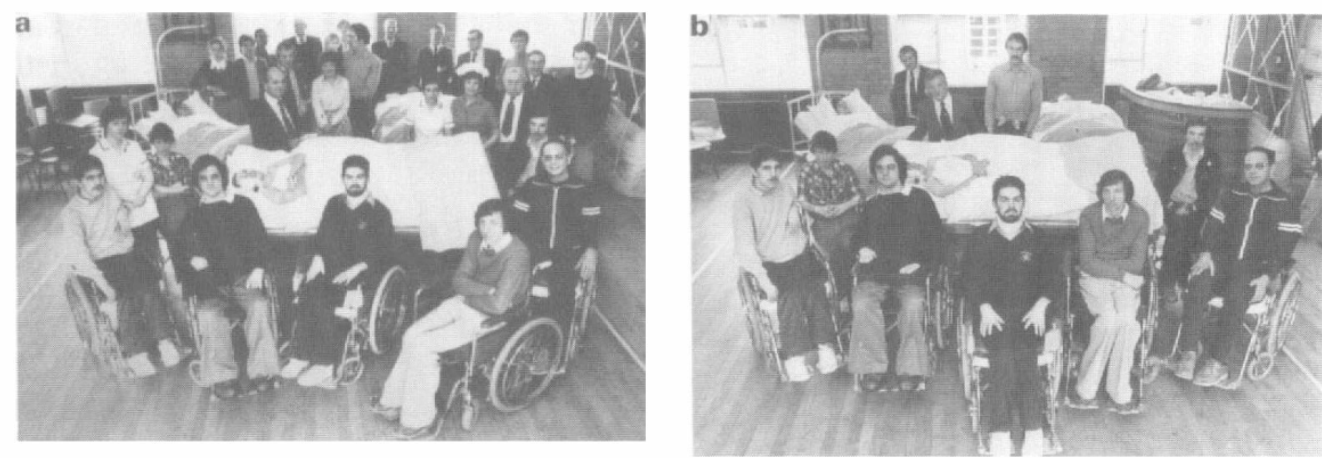

Figure 4 (a) Meeting held in March 1981 at the NSIC. There are many paralysed players. Roger Uttley (national coach), Phil Blakeway and Dr Lewis Cannell (former internationals) can be seen along with Dr Leon Walkden (medical officer of the England Rugby Union). (b) Meeting held in March 1981 at the NSIC. There are many paralysed players. Phil Blakeway and Roger Uttley (national coach) can be seen along with Leon Walkden. (With acknowledgements to The Daily Express.)

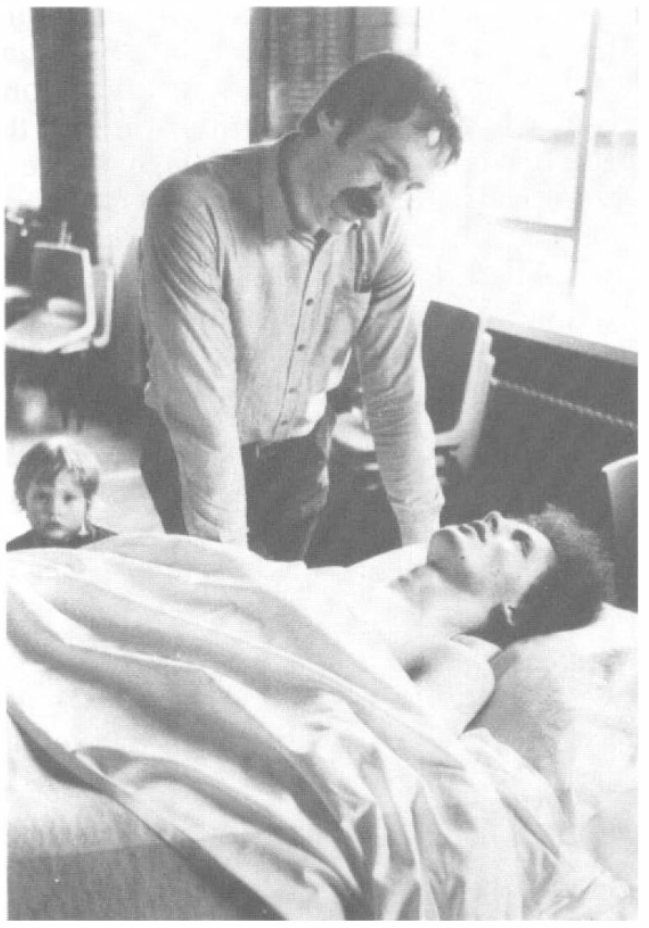

Figure 5 Roger Uttley (national coach) talking to a player when he was a patient at the NSIC during a meeting in March, 1981. (With acknowledgements to The Daily Express.)

notice and set up a committee of which the medical author (JRS) was a member and it was accepted and appreciated that injuries to the cervical spine were always

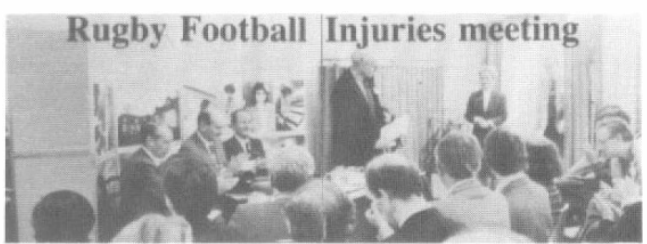

Figure 6 Meeting held at the Chiltern Hospital in 1983. The late Kendall Carpenter, president of the RFU is addressing the audience. (With acknowledgements to the Family Magazine, American Medical International.)

caused by severe forces applied to the crown of the head which is transmitted through to the cervical spine, resulting in a fracture or a dislocation of the cervical spine. If shoulders were not allowed to dip below waist height injuries would be reduced. This was critical.

Within 4 months the English Rugby Union carried out a series of experimental games at Twickenham in April 1983 and produced a series of changes in the interpretation of the laws for schools supported by instructional pamphlets to make the game safer. The pamphlets advised that the shoulders should not dip below the waist height. In the scrummage the players should remain on their feet, tackle correctly and adopt the correct attitude towards the game. Ruck and mauls should not continue for so long. 


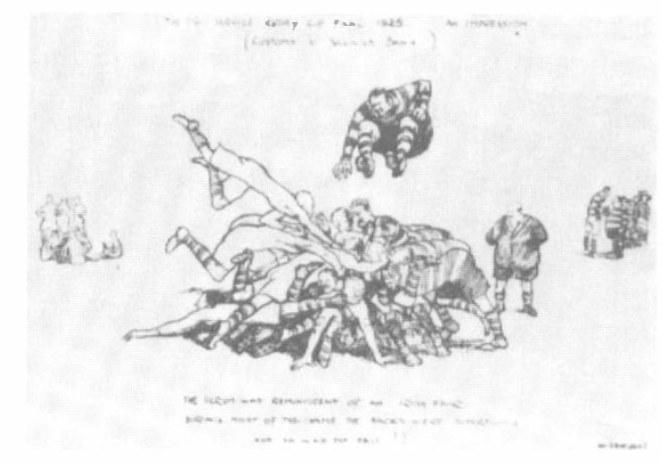

Figure 7 This picture drawn in 1925, although humorous, does get the flavour of rugby played at that time. The players jumped on top of each other and subsequently had their necks broken. (Acknowledgements to Roland Batchelor: $A$ 20th-Century View of the Human Comedy, by Patricia Jarrett. Also acknowledgements to Chris Beetles).

The emphasis was now on the safety of the players (Fig 7). These changes in the laws were adopted at the under 19 level as of September 1st in England only. These changes were then adopted by the International Rugby Football Board for the commencement of the 1986/1987 season throughout the world. A dramatic fall in admissions with broken necks was noted at one centre and nationally in England only.

\section{Conclusion}

We believe that the detailed medical analysis of the causation of rugby injuries has played the foremost part in bringing about reforms to make the game safer.
The evidence fell on the enlightened and receptive ears of the administrators of the game in England, who brought about legislation to make the game safer. They were supported by the New Zealand Board. Rugby administrators in other countries have not been so receptive and in fact have been antagonistic towards spinal injury doctors' attempts to reduce injuries.

As a result of the legal contribution the administrators and organizers of the game have been put on notice that the game is to be conducted properly with due safeguards. It has been demonstrated that unless the game is cleaned up, taught better and managed better, there will be more court cases.

The role of parents has been crucial but understated. While an adult may take a reasonable, informed decision, accepting the risks of a game, a child is in no position and may be under compulsion and moral pressure to play the game. Four-fifths of the rugby players in the United Kingdom are at school. If the game was abolished in schools it would wither in England and there is a fear that the game might be banned as a result of parental stimulus bringing in legislation to make the game safer.

\section{Acknowledgements}

We wish to thank Dr HL Frankel, Mr B Gardner and $\mathrm{Mr}$ Isaac Nuseibeh for allowing us to report on their cases. We would also like to thank Mr Don Rutherford, Mr Ian Beer and Mr Easeby of the Rugby Football Union for their assistance during the preparation of this paper. The views expressed are the views of the authors.

\section{References}

1 O'Connell TCJ (1954) Rugby injuries and their prevention. A review of 600 cases. J Irish Med Assoc 34: 20-26.

2 Silver JR (1984) Injuries of the spine sustained in rugby. BMJ 288: 37-43.

3 Nicholl JP, Coleman P, Williams BT (1991) A National Study of the Epidemiology of Exercise-Related Injury and Illness: A Report to the Sports Council. Medicine Care Research Unit, Department of Public Health and Medicine, University of Sheffield Medical School.

4 Scher AT (1990) Rugby injuries of the cervical spine and spinal cord. S Afr J Sports Med 5: 9-14.

5 Calcinai C (1986) Spinal injuries, what do we know, and what should we do? International Rugby Football Board, medical presentation.

6 Vanderfield G (1987) Spinal injuries in rugby football: vital statistics over the last ten years. Paraplegia 25: 410.

7 Silver JR (1993) Spinal injuries in sports in the UK, Br J Sports Med 27: 115-120. 
8 Roaf RA (1960) A study of the mechanics of spinal injuries, J Bone Joint Surg Br 42: 810-823.

9 Bauze RJ, Ardran GM (1978) Experimental production of forward dislocation in the human cervical spine. J Bone Joint Surg Br 60: 239-245.

10 Mahale YJ, Silver JR, Henderson NJ (1993) Neurological complications of the reduction of cervical spine dislocations. J Bone Joint Surg Br 75: 403-409.

11 Taylor AR (1951) The mechanism of injury to the spinal cord in the neck without damage to the vertebral column. J Bone Joint Surg Br 33: 543-547.

12 Torg JS, Pavlov H, Genuario SE et al (1986) Neurapraxia of cervical spinal cord with transient quadriplegia. J Bone Joint Surg Br 68: 1354-1370.

13 Symonds, Sir Charles (1953) The interrelation of trauma and cervical spondylosis in compression of the cervical cord. The Lancet 7 Mar: 451-454.

14 Denis F (1983) The three column spine and its significance in the classification of acute thoracolumbar spinal injuries. Spine 8: 817-831.

15 Ravichandran G, Silver JR (1982) Survival following traumatic tetraplegia. Paraplegia 20: 264-269.

16 Baker JHE, Silver JR (1987) Hysterical paraplegia. J Neurol Neurosurg Psychiatry 50: 375-382.

17 Silver JR (1979) Rugby injuries to the cervical cord. BMJ 1: 192-193.

18 Kinkade J (1979) Rugby football injuries to the cervical cord. Medical Officers of Schools Association, Chandos Street, London W1. (Letter to the headmasters of public schools in Northern Ireland).

19 Silver J, Davies JE, Walkden L et al (1979) Letter to public schools. Medical Officers of Schools Association, Chandos Street, London W1. 